$\xi=$

\title{
Air Conditioning for Smart Home Energy Management System
}

\author{
A. Ashraf ${ }^{1}$, M. Faisal ${ }^{2 *}$, K. Parvin ${ }^{3}$, Pin Jern Ker ${ }^{4}$, M. A. Hannan ${ }^{5}$ \\ ${ }^{1}$ Department of Electrical Power Engineering, College of Engineering, University Tenaga Nasional, 43000, Kajang, \\ Malaysia \\ *Corresponding author E-mail: M. Faisal (fsl3319@gmail.com)
}

\begin{abstract}
Smart load management system with an advanced metering infrastructure operates to monitor the electricity consumption by the load and transferring data to the utility grid. It has direct benefit to the end-users by managing the load. This system has incorporated with home appliance for achieving the goal of home energy management system (HEMS) such as efficient energy utilization of house by avoiding the wastage. Efficient loading system can strengthen the efficient power utilization and thus can save the economy greatly. Air conditioner (AC), thermostat associated with a room were selected for this purpose as they have the high demand of electricity consumption. This study mainly focuses on developing the mathematical model and simulate it for the considered home appliances to assess the trend of electricity consumption. Research proved that, considering the ambient temperature developed model can provide the specific instructions for automatic controlling of the appliances which will save the electricity consumption and utility bill of end-users compare to the manual operation of the system. Matlab /Simulink software was used to implement and justify the model.
\end{abstract}

Keywords: Automatic control; Electricity consumption; Grid; Smart meter; Utility bill.

\section{Introduction}

Smart loading system enables us to control the load appliances for home energy management system (HEMS). It enables the both way communication between the meter and controlling system of the loads based on the demand and supply. It has the ability to gather data for maintaining the demand response (DR). The data can be transferred through power line communication (PLC), cellular network or ZigBee system. Recently, residential HEM with DR has attracted the attention of the researchers [1]. Different developed and developing countries have taken the step of DR programs to control the electricity consumption for reducing the electricity cost [2], [3].

Previous researches reveal that DR has strong contribution to improve the HEMS in the domestic sector. DR can be defined as the changes in total amount of energy consumption depending on the price of electricity based on the load demand [4]. Peak shaving and load shifting has strong contribution for prosumers to achieve the goal [5]. Data received by the metering system from the load can be used to control the switching of the appliances and thus save the energy.

Several studies have been investigated to make the best use of home energy with minimum wastage. Advanced metering system (AMI), smart home appliances with automatic control of loads, smart sensor technologies etc. [6]. Traditional metering system has several disadvantages such as load monitoring, reliability and also a number of employer needs to be employed to process the billing. Moreover, there is some energy loss in the conventional system. Smart meter allows the relationship between the smart loads and producers with the time of information and customer identity. The usage of energy depends on the habits and culture of the users. Nevertheless, this studies has some limitation to make a thermal comfortable smart home management system for the customer. Saving the maintenance and operational cost and online billing system can attain the customer attention to use the smart load management system for their home. Therefore the objectives of this research can be designed to develop a model for the electrical appliances to operate by HEMS. Moreover, a comprehensive analysis will be proposed for saving the energy and reducing the cost based on the use of the appliances.

\section{Home Energy Management System}

Traditional loading system needs manual switching systems that required human involvement, time consumption and power losses due to switching and unnecessary turn ON of loads. Therefore, in modern distribution networks, smart load management system with the advanced metering infrastructure is assumed to be the key sources for real-time monitoring of data. Evaluating the collected data of energy usage, meters can control the power flow of the customer house appliances depending on the voltage and power requirement of that particular loads [7], [8], [9]. Fig. 1 shows a schematic diagram of HEMS with grid system, demand response system, controller, appliances and renewable sources.

Luis et al proposed a model to control the loads with the smart metering system that can operate based on the DR characteristics [10]. This system showed a significant contribution in controlling the energy usage. Here, peak demand and time shifting method has been introduced to improve the system reliability and reduce the costs of the consumers. However, consumer's comfort was an unsolved issue in this research. In Table 1 shows a comprehensive review on previous researches of HEMS. 


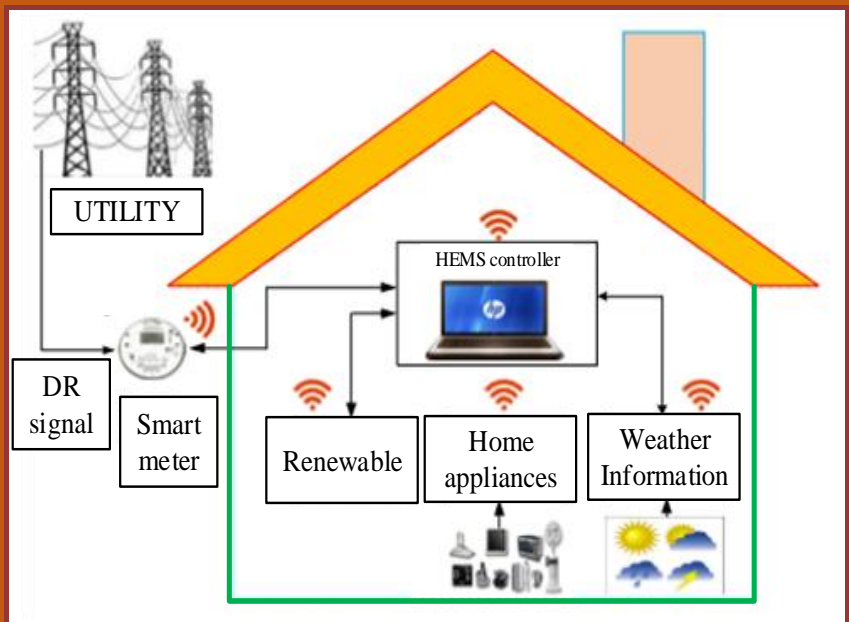

Fig. 1: Schematic diagram of HEMS

Table 1: Review on previous researches of HEMS

\begin{tabular}{|l|l|}
\hline Authors & Contribution of the research \\
\hline Han et al. [7] & $\begin{array}{l}\text { Proposed a remote controlled HEMS } \\
\text { using infrared technology }\end{array}$ \\
\hline Pipattanasomporn et al. [11] & $\begin{array}{l}\text { Developed an Intelligent home sys- } \\
\text { tem with demand response analysis to } \\
\text { control the energy usage and reduce } \\
\text { the electricity cost }\end{array}$ \\
\hline Di Giorgio and Pimpinella [12] & $\begin{array}{l}\text { Smart HEM controller depending on } \\
\text { the event-driven binary linear optimi- } \\
\text { zation technique }\end{array}$ \\
\hline Dittawit and Aagesen [13] & $\begin{array}{l}\text { Proposed an adaptable home man- } \\
\text { agement system between the power } \\
\text { capacity and energy usage }\end{array}$ \\
\hline Missaoui et al. [14] & $\begin{array}{l}\text { Developed A model for managing } \\
\text { home energy without affecting the } \\
\text { customer choices }\end{array}$ \\
\hline Shahgoshtasbi and Jamshidi [15] & $\begin{array}{l}\text { Building EMS for determining the } \\
\text { best energy efficiency to control the } \\
\text { energy usage }\end{array}$ \\
\hline Zhang et al. [16] & $\begin{array}{l}\text { Proposed an artificial bee colony } \\
\text { optimization algorithm to improve } \\
\text { the HEMS }\end{array}$ \\
\hline
\end{tabular}

\section{Modeling for AC and Room}

The proposed system of this research consists of an AC, thermostat (controller), and a room as an environment. The difference of room temperature and ambient temperature is a strong determinant in controlling the heating and cooling system of the room. Because, thermostat operates based on this temperature difference. Fig. 2 shows the block diagram integrating the room, thermostat and $\mathrm{AC}$.

\subsection{Modelling of AC Heat Gain}

Air-condition dissipates the thermal energy through the convection method of the cooled air. This thermal energy is a loss for the system. Therefore, considering the mass of air, $m A C_{a i r}$ the equation of heat gain $\left(Q_{\text {aircon }}\right)$ can be written as,

$Q_{\text {aircon }}=m A C_{\text {air }}\left(T_{\text {aircon }}-T_{r}\right)$

Where, $T_{\text {aircon }}$ and $T_{r}$ denote the air temperature of $\mathrm{AC}$ and room temperature. The rate of thermal energy loss from the $\mathrm{AC}$ can be expressed as,

$\frac{d\left(Q_{A C}\right)}{d t}=\frac{d\left(m A C_{\text {air }}\right)}{d t}\left(T_{\text {aircon }}-T_{r}\right)$

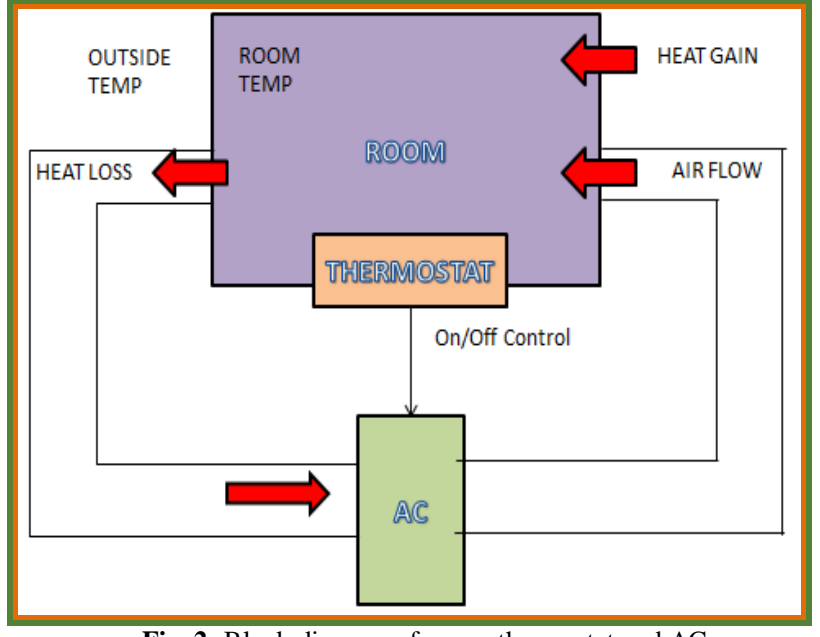

Fig. 2: Block diagram of room, thermostat and AC

As the mass of air with respect to per unit value of time is fixed, simplifying the equation (2) by substituting the $d m A C_{a i} / d t$ with a constant $M A C_{\text {air }}$ we can get,

$\frac{d\left(Q_{A C}\right)}{d t}=M A C_{a i r}\left(T_{a i r c o n}-T_{r}\right)$

\subsection{Modelling of Room}

For room, thermal energy gain $\left(Q_{r}\right)$ takes place by the conduction mechanism through the walls and windows. Therefore, equation of thermal energy gain can be expressed as,

$Q_{r}=\frac{k A\left(T_{\text {outside }}-T_{r}\right) t}{D}$

Therefore, rate of thermal gain can be expressed as,

$\frac{d Q_{r}}{d t}=\frac{k A\left(T_{\text {outside }}-T_{r}\right)}{D}$

Simplifying the equation (5) by replacing $k A / D$ with $l / R$ we can get,

$\frac{d Q_{r}}{d t}=\frac{\left(T_{\text {outside }}-T_{r}\right)}{R}$

Where $R$ is the thermal resistance of the room.

\subsection{Modelling of Temperature}

The complete expression of rate of temperature change in a room can be found by subtracting the rate of heat loss from the rate of heat gain. Therefore, the equation can be written as:

$$
\frac{d T_{r}}{d t}=\left(\frac{1}{{\text { mroom } A C_{\text {air }}}}\right)\left(\frac{d Q_{A C}}{d t}-\frac{d Q_{r}}{d t}\right)
$$

\section{Simulation Design Analysis}

A Matlab/Simulink model that shown in fig. 3 is developed by integrating all the three components (AC, Thermostat and Room). Rate of heat gain of the room is considered during the cooling 
system of the room component. For this purpose, room temperature was fixed at $24^{\circ} \mathrm{C}$ while the natural temperature has been presented as a variable parameter. In the diagram, sine wave represents the natural temperature. After simulation the output is compared with the theoretical value calculated by the developed model. Simulation is performed in both individual and integrated mode.

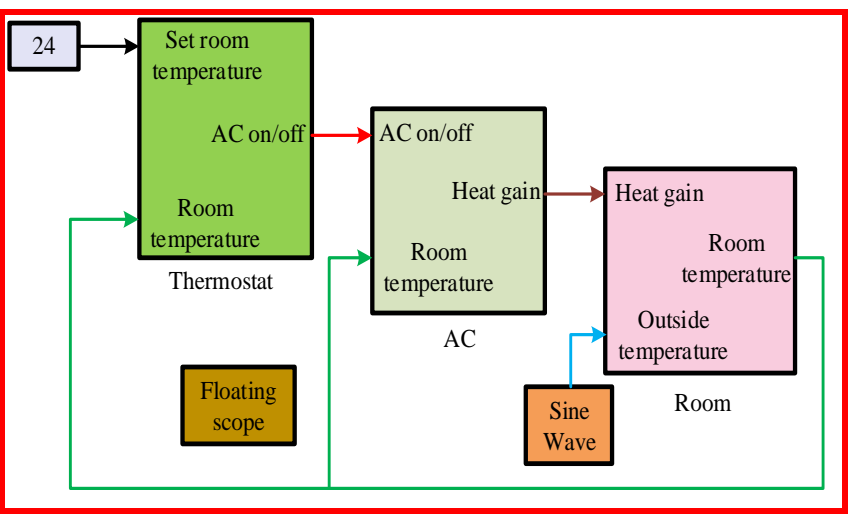

Fig. 3: Matlab/ Simulink model of the proposed system

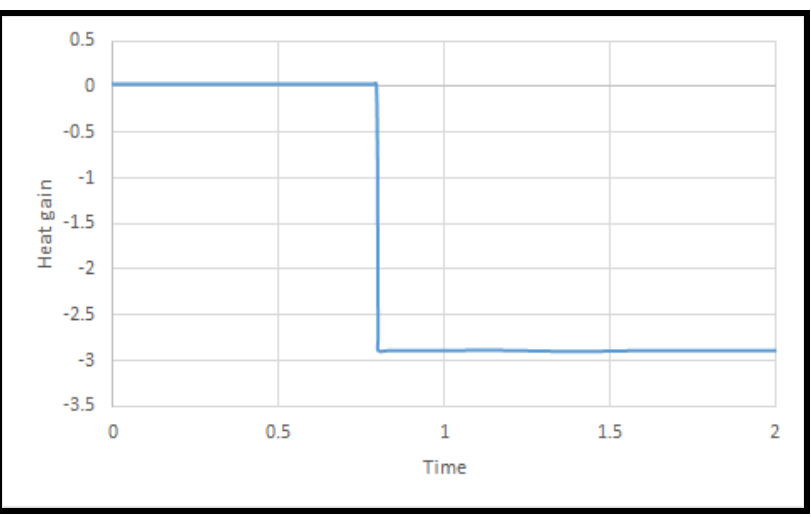

Fig. 4: Simulation for AC component

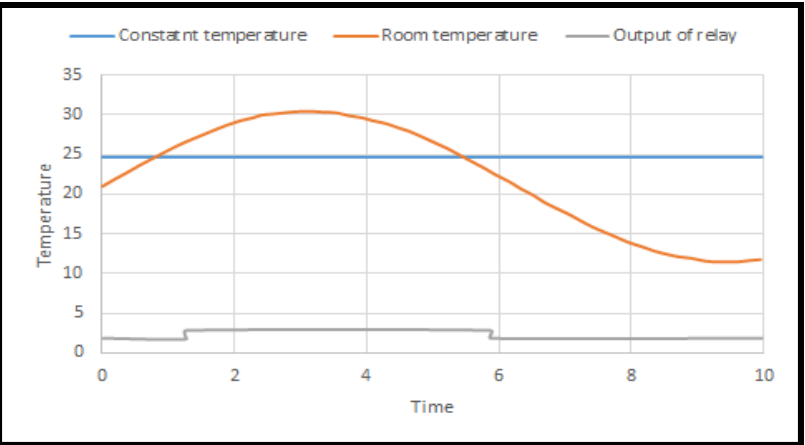

Fig. 5: Simulation for thermostat component

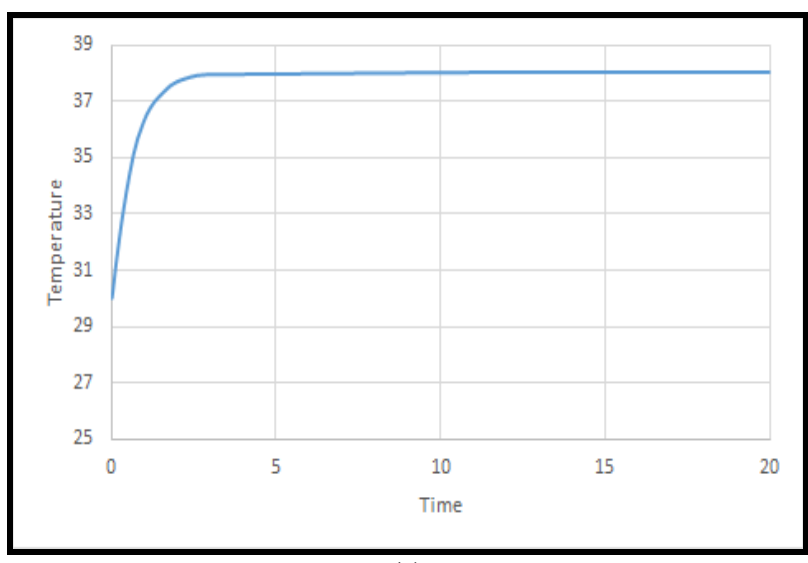

(a)

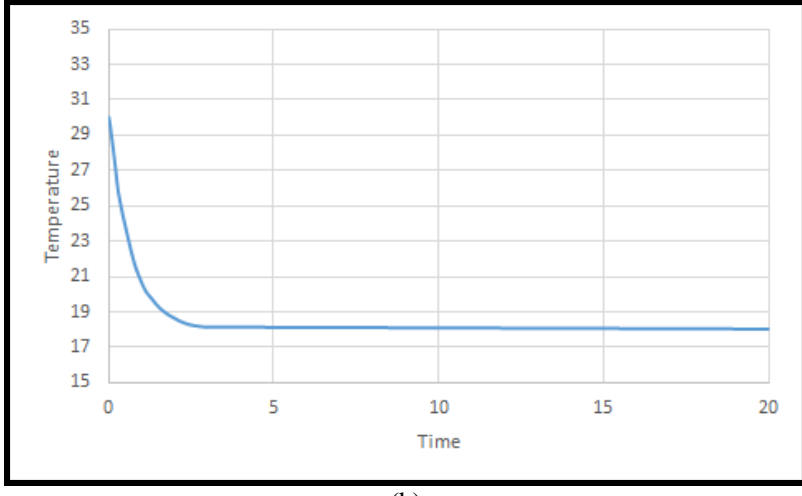

(b)

Fig. 6: Simulation for room component

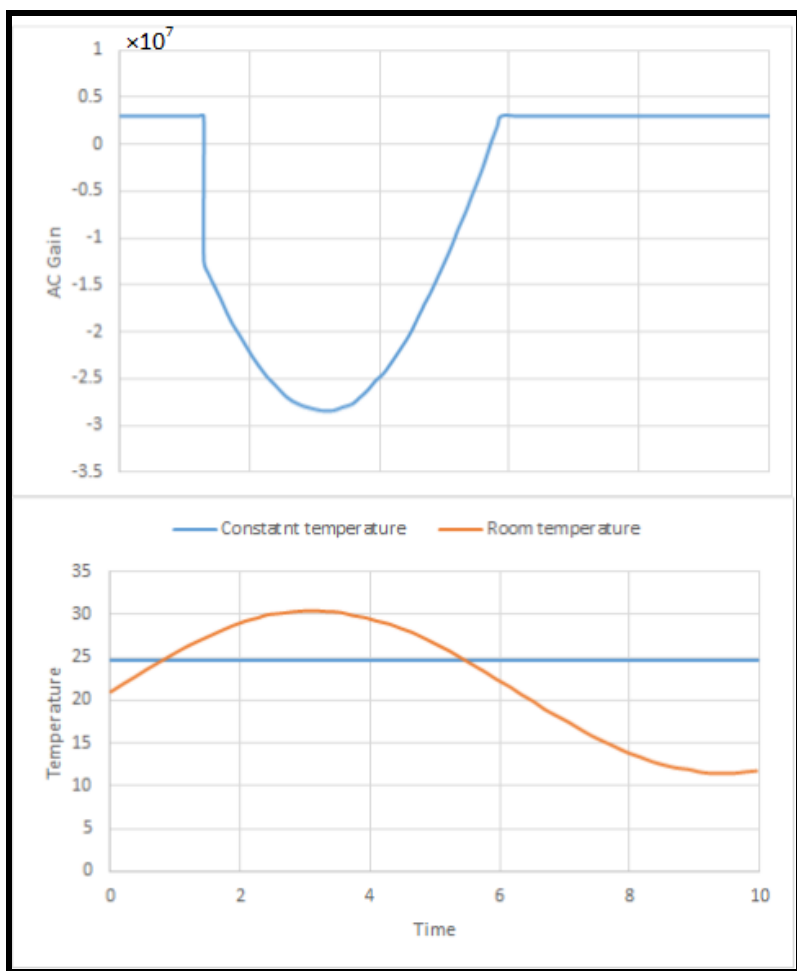

Fig. 7: Simulation for Integrated AC and thermostat

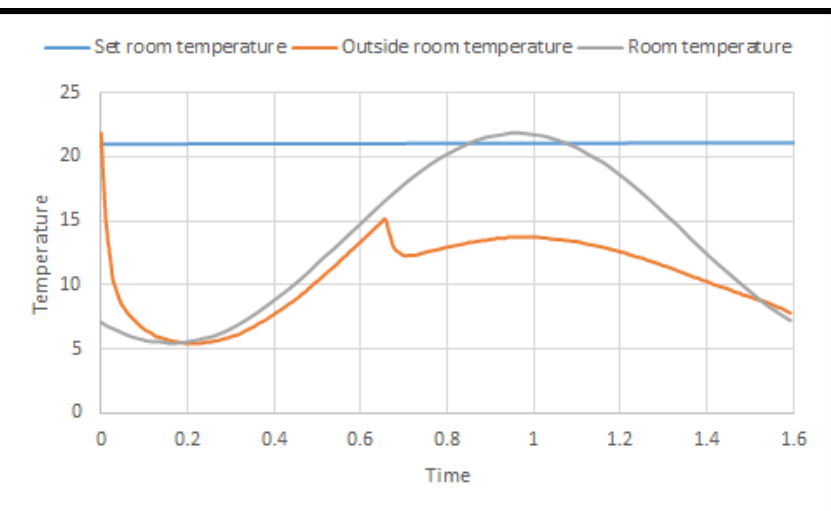

Fig. 8: Wave shapes when all the three components are integrated

The calculated value of AC heat gain is $-2.895 \times 10^{7}$. Simulation output from fig. 4 reveals that, $\mathrm{AC}$ heat gain is almost equal to with the value of $-2.9 \times 10^{7}$. Negative sign denotes the heat loss of room while AC remains switched ON. Therefore, room starts to cool and becomes comfortable.

Fig. 5 describes the output of thermostat based on the difference of room temperature and natural temperature. If room temperature goes above the environment temperature, relay is turned $\mathrm{ON}$ and send the start signal to $\mathrm{AC}$ for operation. AC is turned $\mathrm{ON}$. When 
room temperature goes below the natural temperature, relay gives the OFF signal to AC, therefore, AC is turned OFF. Therefore, the simulation validates the expected outcome.

Theoretically, if the $\mathrm{AC}$ is turned $\mathrm{OFF}$, room temperature starts to increase to become equal to the natural temperature. Heat from environment is diffused into room by conduction method through wall and windows. If the room temperature is higher than the outside temperature, the opposite phenomena occurs. Simulated output in fig. 6 reveals that, if $\mathrm{AC}$ is turned OFF, room temperature starts to rise (from $30^{\circ} \mathrm{C}$ ) to become equal to the outside temperature and saturated at about $38^{\circ} \mathrm{C}$ (outside temperature). Again, if outside temperature $\left(18^{\circ} \mathrm{C}\right)$ is lower than the room temperature, room temperature starts to decrease (from $30^{\circ} \mathrm{C}$ ) to become equal to the outside temperature $\left(18^{\circ} \mathrm{C}\right)$ and becomes constant.

Fig. 7 illustrates the output of integrated $\mathrm{AC}$ and Thermostat. First graph reflects the $\mathrm{AC}$ gain and lower graph describes the constant set temperature and variable temperature of the room. It shows that, heat gain is constant to a particular value for a certain period and starts to decrease to reach to $-2.9 \times 10^{7} \mathrm{~J}$. It occurs as AC becomes turned $\mathrm{ON}$ when room temperature exceeds the fixed temperature. Next, the gain start to increase again and reach the initial position.

Fig. 8 describes the behavior when all components have been incorporated. Initially, it is assumed that set room temperature is almost equal to the outside temperature and $\mathrm{AC}$ remains switched OFF. However, when AC is turned ON, room temperature gradually tends to decreases. From fig, the wave shape of outside temperature is different from the room temperature. Therefore, to control the room temperature at desired level, the air-condition needs to be switched ON or OFF based on the room temperature which will increase the customer comfortability.

\section{Conclusion}

Considering the matlab simulation output and theoretical result of heat gain, it can be inferred that, smart load management system is a most suitable technique for home energy management system. Proposed mathematical model for AC can be utilized to provide definite information for automatic control of AC. Systems can be designed in such a way that, AC will operate based on its own schedule depending on the environmental and room temperature, which will facilitate to reduce the energy loss and reduce electricity bill of consumers. This is the definite advantage compare to the traditional manual loading system. Therefore, the objective of proposing the smart loading system for HEMS has been achieved by automatic control of loads such AC. In this research, smart load modelling with a scheduling controller for has been introduced to switch ON or OFF the appliances. Therefore, customer preference of comfortable room with reduced energy consumption and energy loss is a greater advantage of this study.

\section{Acknowledgement}

The authors acknowledge the financial support provided by Universiti Tenaga Nasional under the grant code 10289176/ SMART/ 2018/02.

\section{References}

[1] N. Kushiro and T. Kondo, "Home Energy Management by Handling Life Event,” no. 25330372, pp. 497-498, 2016.

[2] S. Maharjan, Q. Zhu, Y. Zhang, S. Gjessing, and T. Başar, "Demand response management in the smart grid in a large population regime,” IEEE Trans. Smart Grid, vol. 7, no. 1, pp. 189-199, 2016.

[3] M. M. Jalali and A. Kazemi, "Demand side management in a smart grid with multiple electricity suppliers," Energy, vol. 81, pp. 766$776,2015$.
[4] Safdarian, M. Fotuhi-Firuzabad, and M. Lehtonen, "Benefits of Demand Response on Operation of Distribution Networks: A Case Study," Syst. Journal, IEEE, vol. PP, no. 99, pp. 1-9, 2014.

[5] K. C. Sou, J. Weimer, H. Sandberg, and K. H. Johansson, "Scheduling smart home appliances using mixed integer linear programming," IEEE Conf. Decis. Control Eur. Control Conf., pp. 5144 5149, 2011.

[6] B. Zhou et al., "Smart home energy management systems: Concept, configurations, and scheduling strategies," Renew. Sustain. Energy Rev., vol. 61, pp. 30-40, 2016.

[7] J. Han, C.-S. Choi, and I. Lee, "More efficient home energy management system based on ZigBee communication and infrared remote controls," IEEE Trans. Consum. Electron., vol. 57, no. 1, pp. 85-89, 2011.

[8] S. Uddin, H. Shareef, A. Mohamed, and M. A. Hannan, "An analysis of harmonics from dimmable LED lamps," 2012 IEEE Int. Power Eng. Optim. Conf. PEOCO 2012 - Conf. Proc., pp. 182-186, 2012.

[9] Salam, A. Mohamed, M. A. Hannan, and H. Shareef, “An improved inverter control scheme for managing the distributed generation units in a microgrid," Int. Rev. Electr. Eng., vol. 5, no. 3, pp. 891$899,2010$.

[10] L. I. Minchala-Avila, J. Armijos, D. Pesántez, and Y. Zhang, "Design and Implementation of a Smart Meter with Demand Response Capabilities," Energy Procedia, vol. 103, no. April, pp. 195-200, 2016.

[11] M. Pipattanasomporn, M. Kuzlu, and S. Rahman, “An algorithm for intelligent home energy management and demand response analysis," IEEE Trans. Smart Grid, vol. 3, no. 4, pp. 2166-2173, 2012.

[12] Di Giorgio and L. Pimpinella, "An event driven Smart Home Controller enabling consumer economic saving and automated Demand Side Management," Appl. Energy, vol. 96, pp. 92-103, 2012.

[13] On Adaptable Smart Home Energy Systems [14] Missaoui, R., Joumaa, H., Ploix, S. \& Bacha, S. 2014. Managing Energy Smart Homes According to Energy Prices: Analysis of a Building Energy Management System. Energy and Buildings 71: 155-167.

[14] D. Shahgoshtasbi and M. M. Jamshidi, "A new intelligent neurofuzzy paradigm for energy-efficient homes," IEEE Syst. J., vol. 8, no. 2, pp. 664-673, 2014.

[15] Y. Zhang, P. Zeng, and C. Zang, "Optimization Algorithm for Home Energy Management System Based on Artificial Bee Colony in Smart Grid," pp. 734-740, 2015. 